\title{
Review
}

\section{Faecal calprotectin in inflammatory bowel diseases: a review focused on meta-analyses and routine usage limitations}

https://doi.org/10.1515/cclm-2018-1063

Received September 28, 2018; accepted November 28, 2018; previously published online January 7, 2019

\begin{abstract}
A growing body of evidence has been published about the usefulness of measuring calprotectin in faecal samples (FCAL) in inflammatory bowel disease (IBD) assessment, including diagnosis, monitoring of disease activity and relapse prediction. Several systematic reviews with meta-analyses compiling studies for each particular clinical setting have been carried out in recent years. Most of these were focused on the use of FCAL in IBD diagnosis and showed a relevant role for this marker in selecting patients with gastrointestinal symptoms who would not need a further examination by endoscopy. Although a lesser number of meta-analyses have been performed on the use of FCAL as a surrogate marker of disease activity, a close correlation between FCAL and endoscopic activity of IBD has been shown. With respect to the predictive capacity of FCAL for IBD relapse, a single meta-analysis published indicates that this role is more limited. Furthermore, FCAL thresholds vary considerably depending on the clinical setting and, what is more concerning, among different commercially available assays due to a lack of FCAL concentration interchangeability. Here, we summarise recent publications about the role and limitations of FCAL in IBD, with a special focus on meta-analyses, and give an overview of alternative faecal biomarkers.
\end{abstract}

Keywords: ELISA; faecal calprotectin; inflammatory bowel diseases; meta-analysis; point-of-care testing.

\footnotetext{
*Corresponding author: Emilio J. Laserna-Mendieta, EuSpLM, PhD, Department of Gastroenterology, Hospital General de Tomelloso, Véreda de Socuéllamos, s/n, Tomelloso (Ciudad Real) 13700, Spain; and Clinical Laboratory, Hospital General de Villarrobledo, Villarrobledo, Spain, E-mail: ejlaserna@sescam.jccm.es Alfredo J. Lucendo: Department of Gastroenterology, Hospital General de Tomelloso, Tomelloso, Spain; and Biomedical Research Network Centre for Liver and Digestive Diseases (CIBEREHD), Madrid, Spain
}

\section{Introduction}

Calprotectin is a calcium and zinc-binding protein formed by a heteromeric complex of two subunits, S100A8 and S100A9. Conformation and oligomerisation state of S100A8/A9 is driven by their calcium and zinc-binding properties, which leads to the formation of the physiologically active heterooligomer [1, 2]. It is derived from human neutrophils and monocytes and represents around $60 \%$ of soluble cytosol proteins in human neutrophil granulocytes [3]. Calprotectin was previously known as MRP8/MRP14, cystic fibrosis-associated antigen, calgranulin and S100, and it has been classically considered a defence protein at the epithelial surface level due to its antimicrobial activity depriving microorganisms of transition metals [4, 5]. In addition, it has been associated with antiproliferative and immunomodulatory effects [6-9].

Although calprotectin can be detected and measured in several biological samples such as plasma, urine, saliva, synovial fluid and colonic biopsies, the most extended determinations are carried out in faeces [10, 11]. In fact, calprotectin is considered a surrogate marker of neutrophil turn-over and its levels have been found to be elevated in several inflammatory states, once identified [10].

In the field of Gastroenterology, faecal calprotectin (FCAL) has gained much attention due to its increase in organic gastrointestinal conditions, mainly in inflammatory bowel diseases (IBD), which comprises Crohn's disease (CD) and ulcerative colitis (UC). Its clinical utility as a non-invasive biomarker of inflammation in IBD has been evaluated particularly in the last 15 years and FCAL currently is incorporated as a routine test for IBD diagnosing and monitoring in clinical laboratories, with several commercial tests being available [12-14].

This review is aimed at describing the most recent evidence about the utility of FCAL in several aspects of IBD, including diagnosis, assessment of disease activity and mucosal healing, response to therapy, and capacity to predict relapse and postoperative recurrence. These aspects are viewed with a special focus on systematic 
reviews with meta-analyses carried out for each purpose (Table 1). In addition, we review the differences between the several FCAL assays available in clinical practice, as this is one of the main hurdles for its clinical implementation. Finally, current limitations of FCAL in clinical settings and other alternative biomarkers are discussed.

\section{Utility of measuring FCAL when IBD is suspected}

FCAL is considered a useful marker for IBD diagnosis, especially in screening patients with digestive symptoms that would be submitted for endoscopic assessment. It should be noted that FCAL levels do not allow differentiation between CD and UC [27], and elevated concentrations causing false positive values could be found in several conditions including infections, gastric or colorectal cancer, intestinal lymphoma, eosinophilic colitis or autoimmune enteropathy [28] (see also Section "Current limitations in FCAL routine clinical use" of this review).

The first meta-analysis that evaluated pooled diagnostic precision of FCAL for IBD was published in 2007 [15]. The authors reported an area under the receiver operating characteristics curve (AUROC) of 0.95 for an IBD diagnosis when compared to healthy controls, with better accuracy at a cut-off level of $100 \mathrm{vs.} 50 \mu \mathrm{g} / \mathrm{g}$. However, a subsequent meta-analysis with the same focus determined that the optimal cut-off point for an IBD diagnosis was $50 \mu \mathrm{g} / \mathrm{g}$, which is currently the widely accepted cut-off level to identify patients who are most likely to need endoscopy. This invasive procedure can be safely avoided when FCAL values are below this threshold because the vast majority of patients will not have IBD, even though a delayed diagnosis, due to a false negative result, will occur in $6 \%-8 \%$

Table 1: Meta-analyses about faecal calprotectin performance in inflammatory bowel diseases included in this review; ordered according to when they were cited in the document.

\begin{tabular}{|c|c|c|c|c|c|c|c|c|c|c|}
\hline \multirow[t]{2}{*}{ Meta-analyses } & \multirow[t]{2}{*}{ Year } & \multirow[t]{2}{*}{ Clinical setting } & \multirow[t]{2}{*}{$\mathbf{n}$} & \multicolumn{3}{|c|}{ Patients } & \multirow[t]{2}{*}{ Controls } & \multirow{2}{*}{$\begin{array}{l}\text { Cut-off, } \\
\mu g / g\end{array}$} & \multirow[t]{2}{*}{ Sensitivity } & \multirow[t]{2}{*}{ Specificity } \\
\hline & & & & IBD & UC & CD & & & & \\
\hline $\begin{array}{l}\text { Von Roon et al. } \\
\text { [15] }\end{array}$ & 2007 & $\begin{array}{l}\text { Diagnosis of IBD } \\
\text { (adults and children) }\end{array}$ & 9 & 1267 & 361 & 663 & & 50 & $0.89(0.86-0.91)$ & $0.81(0.78-0.94)$ \\
\hline $\begin{array}{l}\text { Van Rheenen et al. } \\
\text { [16] }\end{array}$ & 2010 & $\begin{array}{l}\text { Diagnosis of IBD in } \\
\text { adults }\end{array}$ & 6 & 670 & & & & $24-150$ & $0.93(0.85-0.97)$ & $0.96(0.79-0.99)$ \\
\hline Menees et al. [17] & 2015 & $\begin{array}{l}\text { Diagnosis of IBD in } \\
\text { adults }\end{array}$ & 8 & 565 & & & $238^{\mathrm{a}}$ & NS & NS & NS \\
\hline Kopylov et al. [18] & 2016 & $\begin{array}{l}\text { Diagnosis of small } \\
\text { bowel CD }\end{array}$ & 7 & & & 463 & & 50 & $0.83(0.73-0.90)$ & $0.53(0.36-0.71)$ \\
\hline $\begin{array}{l}\text { Van Rheenen et al. } \\
\text { [16] }\end{array}$ & 2010 & $\begin{array}{l}\text { Diagnosis of IBD in } \\
\text { children }\end{array}$ & 7 & 371 & & & & $32-100$ & $0.92(0.84-0.96)$ & $0.76(0.62-0.86)$ \\
\hline $\begin{array}{l}\text { Henderson et al. } \\
\text { [19] }\end{array}$ & 2014 & $\begin{array}{l}\text { Diagnosis of IBD in } \\
\text { children }\end{array}$ & 8 & 394 & 149 & 230 & 321 & $50-100$ & $0.98(0.95-1.00)$ & $0.68(0.50-0.86)$ \\
\hline $\begin{array}{l}\text { Degraeuwe et al. } \\
\text { [20] }\end{array}$ & 2015 & $\begin{array}{l}\text { Diagnosis of IBD in } \\
\text { children }\end{array}$ & 9 & 853 & & & & $50-160$ & $0.97(0.92-0.99)$ & $0.70(0.59-0.79)$ \\
\hline Holtman et al. [21] & 2016 & $\begin{array}{l}\text { Diagnosis of IBD in } \\
\text { children }\end{array}$ & 10 & 867 & & & & $50-100$ & $0.99(0.92-1.00)$ & $0.65(0.54-0.74)$ \\
\hline Lin et al. [22] & 2014 & $\begin{array}{l}\text { Evaluation of } \\
\text { disease activity }\end{array}$ & 13 & 1471 & 744 & 727 & & 250 & $0.80(0.76-0.84)$ & $0.82(0.77-0.86)$ \\
\hline Mosli et al. [23] & 2015 & $\begin{array}{l}\text { Evaluation of } \\
\text { disease activity }\end{array}$ & 19 & 2102 & 1069 & 1033 & 397 & $48-280$ & $0.88(0.84-0.90)$ & $0.73(0.66-0.79)$ \\
\hline Mao et al. [24] & 2012 & Prediction of relapse & 6 & 672 & 318 & 354 & & $50-340$ & $0.78(0.72-0.83)$ & $0.73(0.68-0.77)$ \\
\hline Qiu et al. [25] & 2015 & $\begin{array}{l}\text { Post-operative } \\
\text { endoscopic } \\
\text { recurrence }\end{array}$ & 8 & & & 391 & & $100-283$ & $0.82(0.73-0.89)$ & $0.61(0.51-0.71)$ \\
\hline Tham et al. [26] & 2018 & $\begin{array}{l}\text { Post-operative } \\
\text { endoscopic } \\
\text { recurrence }\end{array}$ & 6 & & & 340 & & 150 & $0.70(0.59-0.81)$ & $0.69(0.61-0.77)$ \\
\hline
\end{tabular}

Pooled sensitivity and specificity were reported for those meta-analyses with a range of cut-off values. $n$, number of studies employed in calculation of FCAL performance; IBD, inflammatory bowel diseases; UC, ulcerative colitis; CD, Crohn's disease; NS, not specified; a, it also included 259 patients with irritable bowel syndrome as controls. 
of patients [16]. An even lower FCAL cut-off concentration of $40 \mu \mathrm{g} / \mathrm{g}$ resulted in a very low false negative rate $(\leq 1 \%)$ according to the meta-analysis subsequently performed by Menees et al. [17].

In the particular setting of $\mathrm{CD}$ restricted to the small bowel, FCAL performed well compared to capsule endoscopy. A meta-analysis which compared both techniques showed that FCAL still had a significant diagnostic accuracy for the detection of this particular location of $\mathrm{CD}$ [18]. The common $50 \mu \mathrm{g} / \mathrm{g}$ cut-off displayed an acceptable sensitivity (0.83) which was lower compared to values described for overall IBD (normally above 0.95 ), although a low specificity was reported (0.53), overall providing a negative predictive value (NPV) of $92 \%$.

The utility of FCAL to diagnose IBD in paediatric populations was initially a matter of controversy due to the higher concentrations that were found in healthy infants compared to older children and adults [29-31]. As a result, the capacity of FCAL to exclude IBD was lower in children compared to adults (pooled specificity of 0.76 vs. 0.96 , respectively) [16]. However, subsequent studies demonstrated that FCAL can be a helpful tool for this purpose in the paediatric population. One of the first meta-analysis about this issue showed that FCAL had a high sensitivity (0.98) but modest specificity (0.68) for the diagnosis of IBD in childhood [19]. Similar results were obtained in a second meta-analysis that estimated a pooled sensitivity for FCAL of 0.97 , while only $2 \%$ false negative results were obtained when using the $50 \mu \mathrm{g} / \mathrm{g}$ cut-off concentration in the patient-level pooled analysis [20].

More recently, a meta-analysis including children with suspected IBD showed that FCAL is useful in identifying children at low risk (pooled sensitivity of 0.99) while increased C-reactive protein (CRP) or albumin are more useful to detect children at high risk [21]. Therefore, a low concentration of FCAL had relevant value in avoiding endoscopy also in low risk paediatric patients. Moreover, when added to a basic prediction model based on symptoms only, FCAL was the laboratory marker that achieved a greater increase in the AUROC for paediatric IBD diagnosis in comparison to CRP, erythrocyte sedimentation rate (ESR), platelets, haemoglobin and albumin [32]. The study, which included 1120 patients, also showed that FCAL increased and decreased, more than other biomarkers, the percentages of patients correctly and incorrectly classified at low risk of IBD, respectively.

FCAL performance to avoid unnecessary endoscopies and saving healthcare-related costs when IBD is suspected, was also identified in the meta-analysis by Van Rheenen et al. [16]. The use of FCAL for IBD screening is cost-effective when the pre-test probability is $\leq 75 \%$ for adults and $\leq 65 \%$ for children [33]. The savings reported in this study were greater and the number of patients with delayed diagnosis lower for adults compared to children. In relation to cut-off values, $50 \mu \mathrm{g} / \mathrm{g}$ provided a better diagnostic accuracy, without substantially increasing costs, compared to $100 \mu \mathrm{g} / \mathrm{g}$ [33], although other authors found greater savings by using the latest cut-off point [34]. The use of FCAL was also found to be cost effective when distinguishing IBD from irritable bowel syndrome (IBS) in adults, and IBD from non-IBD in children in an economic modelling study, due to the high NPV of FCAL [35]. This includes the fact that a negative result rules out IBD in most cases, thereby sparing most people from having to undertake invasive and more expense investigations, such as a colonoscopy.

\section{Utility of FCAL to monitor disease activity in IBD}

The accuracy of FCAL to monitor IBD patients after being diagnosed as a surrogate biomarker for clinical, endoscopic and histological activity has been widely evaluated [36]. An early meta-analysis on this topic by Lin et al. included 13 prospective studies evaluating the accuracy of FCAL for differentiating between patients with active IBD and those in remission, using endoscopy as a reference standard. FCAL exhibited an AUROC value of 0.89 in distinguishing between active and inactive IBD, being slightly higher for UC than for CD. A cut-off value of $250 \mu \mathrm{g} / \mathrm{g}$ was proposed, having the highest specificity $(0.82)$ together with an acceptable sensitivity (0.80) to define endoscopic disease activity [22]. A later and larger meta-analysis compared three non-invasive biomarkers (CRP, FCAL and faecal lactoferrin) with endoscopic activity as the gold standard; FCAL exhibited the highest combined values of pooled sensitivity and specificity $(0.88$ and 0.73 , respectively) [23].

Subsequent studies analysing FCAL as a surrogate marker of IBD activity were in agreement with the findings of these two meta-analyses. However, the previous results do not eliminate the prognostic value of patient's symptoms to estimate the endoscopic activity of IBD, and despite FCAL being a better surrogate marker of endoscopic inflammatory activity than CRP and patientreported outcomes (PRO), a combination of PRO and FCAL has resulted in increased AUROC compared to FCAL alone [37].

Even when endoscopy suggests mucosal healing, evidence of histologic activity in colonic mucosal biopsies 
may remain. Histologic healing requires the absence of inflammation or structural changes, and has been linked to improved clinical outcomes. Compared to endoscopic mucosal healing, histological remission better predicts lower rates of corticosteroid use and acute severe flare ups requiring hospitalisation - over a median of 6 years of follow-up [38] - and also reduces the need for surgery and the risk of developing cancer [39]. Thus, histological mucosal healing as a target distinct from endoscopic healing in IBD, has been proposed to improve disease prognosis further [40]. The accuracy of FCAL in identifying those IBD patients in clinical and endoscopic remission, who still have histologic features of inflammation, has also been evaluated. FCAL correlated well with mucosal healing both in UC and colonic $\mathrm{CD}$, with the AUROC being 0.95 for histological remission [41]. The capacity of FCAL to detect histologic inflammatory activity was reduced in a series of patients with UC (the AUROC being 0.755) when this was more strictly defined [42]. Similar results were found in another study defining histologic activity based on epithelial neutrophils, as FCAL displayed an AUROC value of 0.754 to identify histologic inflammation in patients with UC in clinical and endoscopic remission [43]. Likewise, FCAL values were useful in identifying patients with UC who had endoscopic and histologic features of mucosal healing, showing a high NPV, and its elevations also correlating with endoscopic and histologic inflammatory activity [44].

In children with IBD, FCAL levels were also significantly higher among patients with endoscopically active diseases compared to those in endoscopic remission [45], and it has also been shown that FCAL is a reliable marker of histologic relapse for both CD and UC, $275 \mu \mathrm{g} / \mathrm{g}$ being the optimal cut-off point for overall IBD, but higher (462 $\mu \mathrm{g} / \mathrm{g}$ ) for CD [46]. FCAL was found as the most accurate tool (with sensitivity of 0.94 , specificity of 0.64 and NPV of $87 \%$ ) to detect the presence of active mucosal inflammation in paediatric IBD when compared to clinical scores, CRP and ESR [47].

\section{Utility of FCAL in predicting remission and anticipating relapse of IBD}

Whether detection of elevated FCAL concentrations in a patient in clinical remission could anticipate a relapse in IBD was first analysed by Tibble et al. in 2000 [48]. Publications dealing with this issue up to the year 2012 were summarised in a meta-analysis of six prospective studies [24]. Remission and relapse criteria were based exclusively on clinical activity indexes and FCAL was measured during the clinical remission phase to predict disease relapse during the following year of prospective followup. Pooled sensitivity and specificity of FCAL levels to predict clinical relapse were 0.78 and 0.73 , respectively, with similar predictive capacities for CD and UC. The suboptimal predictive capacity of FCAL in this setting can be related to the well-known lack of correlation between symptom scores in traditional clinical activity indexes and endoscopic activity in IBD [49].

Subsequent studies integrated both symptomatic and endoscopic remission as the reference standard with which to compare FCAL levels. A prospective study carried out in patients with UC in clinical and endoscopic remission assessed the ability of FCAL to predict relapse in 3and 12-month periods, rigorously defined as the presence of blood in stools and a Mayo endoscopic subscore equal or higher to 1 with histologic confirmation [50]. The ability to predict recurrence over 3 months after FCAL measurement increased with growing values of this faecal biomarker, but its accuracy was, overall, low as a cut-off level of $250 \mu \mathrm{g} / \mathrm{g}$ had a global accuracy, sensitivity, specificity and NPV of 0.78, 0.45, 0.85 and 0.88, respectively. Similar results (good specificity and NPV, but low sensitivity) were later described in a subsequent study where baseline FCAL level above $321 \mu \mathrm{g} / \mathrm{g}$ predicted disease relapse at both the 6- and 12-month follow-up points in remission patients with UC [42]. Likewise, in IBD patients with mucosal healing, sustained low values of FCAL (below $56 \mu \mathrm{g} / \mathrm{g}$ ) were found to predict absence of relapse during a median follow-up of 11 months, with a sensitivity of 0.64 , a specificity of 1.00 , an NPV of $100 \%$, and a positive predictive value of $20 \%$ [51].

A systematic review that retrieved six studies regarding the utility of measuring FCAL asymptomatic patients with IBD to predict disease exacerbation at an early stage, found that subjects with repeated FCAL concentration above the upper limit of the normal range had a 53\%$83 \%$ probability of developing disease relapse within the next 2-3 months, while those with repeated normal FCAL values had a $67 \%-94 \%$ probability of remaining in remission during the same period [52]. Because of the limited number of studies included in this systematic review, the different FCAL assays and the variations in normal FCAL concentration ranges used, the authors were not able to derive an optimal cut-off point. In agreement with this study, monitoring of FCAL levels every 3 months was suggested as a useful tool to predict clinical relapse in IBD by Zhulina et al. [53]. 
In children with quiescent CD, a FCAL level above $400 \mu \mathrm{g} / \mathrm{g}$ was associated with clinical relapse within the following 9 months, while $89 \%$ of children with FCAL values below that threshold remained in remission during the same period [54]. A similar FCAL cut-off, $500 \mu \mathrm{g} / \mathrm{g}$, was found to correlate with an increased risk of progressing to symptomatic relapse within a 3-month period (53\% for FCAL above this threshold vs. $12 \%$ for FCAL below it) in teenagers with IBD who report a full control of the disease [55]. Good performance was also reported recently for an IBD paediatric cohort in clinical remission for at least 3 months, as FCAL showed high level accuracy (AUROC of 0.82) to predict symptomatic relapse within 6 months, with an NPV of $96 \%$ for $350 \mu \mathrm{g} / \mathrm{g}$ cut-off concentration [56]. Otherwise, lower performance of FCAL levels to predict relapse was described for children in clinical remission, with an NPV of $75 \%$ for FCAL values below $100 \mu \mathrm{g} / \mathrm{g}$ to remain into clinical remission for a subsequent year [57].

\section{Utility of FCAL to predict response to anti-TNF $\alpha$ therapy}

After being demonstrated as a reliable indicator of activity and severity in IBD, and also in predicting its clinical course, several studies later evaluated the potential of FCAL in anticipating response to therapy. The value of FCAL to predict response to anti-TNF $\alpha$ therapy was assessed in several papers after initial research in a series of UC patients with high levels of FCAL who underwent an emergency colectomy due to failure to respond to medical therapy with corticosteroids or infliximab (IFX) [58]. However, the potential utility of FCAL for other first line IBD therapies has been poorly evaluated.

One of the first studies on this topic showed a rapid decrease in FCAL levels, during induction with IFX, in patients with UC who responded to therapy and among whom FCAL measurement at week 10 correlated with endoscopic remission, with an AUROC of 0.91 [59]. A subsequent study in UC that measured FCAL every 4 weeks during maintenance therapy with IFX, observed that all patients with sustained deep remission after 1-year follow-up had permanent FCAL levels below $40 \mu \mathrm{g} / \mathrm{g}$ [60]. In the same study, elevated FCAL levels during anti-TNF $\alpha$ therapy were also useful to predict a clinical flare up, as these patients already had significantly higher FCAL levels 3 months before the flare up. In fact, two consecutive FCAL measurements above $300 \mu \mathrm{g} / \mathrm{g}$ within 1-month interval were identified as the best predictors of flare ups (sensitivity of 0.62 and specificity of 1.00) during maintenance therapy with IFX in UC.

In patients with $\mathrm{CD}$ treated with anti-TNF $\alpha$ drugs, FCAL was also more reliable than CRP and clinical indexes in predicting endoscopic remission (sensitivity of 0.84 and specificity of 0.74 ) [61]. For IBD patients overall under anti-TNF $\alpha$ treatment, a normal FCAL after induction predicted sustained clinical remission in the majority (84\%), and a cut-off level of $139 \mu \mathrm{g} / \mathrm{g}$ had a sensitivity of 0.72 and a specificity of 0.80 in predicting clinically active disease after 1 year [62]. Similar findings were reported in a prospective Spanish study, as FCAL below $130 \mu \mathrm{g} / \mathrm{g}$ was the optimal cut-off level to predict remission (sensitivity of 1.00 , specificity of 0.80 and NPV of $100 \%$ ), while FCAL higher than $300 \mu \mathrm{g} / \mathrm{g}$ predicted relapse over the following 4 months [63].

The predictive capacity of FCAL in anticipating IBD recurrence after stopping anti-TNF alpha drugs has also been evaluated. High FCAL concentrations were associated in several studies with an increased risk of relapse after anti-TNF drug withdrawal. The STORI trial found that a FCAL concentration above $300 \mu \mathrm{g} / \mathrm{g}$ constituted an independent risk factor for relapse after IFX discontinuation in patients with CD [64]; a prospective multicentre Finish study detected that FCAL levels increased significantly at 2, 4 and 6 months before endoscopic relapse, while constantly normal FCAL concentrations during follow-up had a high prediction for clinical and endoscopic remission [65]. In a large cohort from the UK, increased FCAL levels over $50 \mu \mathrm{g} / \mathrm{g}$ at the moment of drug withdrawal was an independent predictor - aside from patients' demographic and clinical characteristics - for CD relapse within the following 2 years, with a hazard ratio of 2.95 (1.22-7.12) [66]. In contrast, Bortlik et al. did not find an association between low FCAL levels and maintenance of remission in Czech patients with CD after anti-TNF $\alpha$ discontinuation using a multivariate model [67].

\section{FCAL to detect postoperative endoscopic recurrence in CD}

Half of patients with $C D$ will require a resection of the affected bowel segment, most commonly, an ileocolic resection, within 10 years post diagnosis. This figure may increase up to $80 \%$ over the course of their lives [68]. However, surgery does not cure $\mathrm{CD}$ and recurrence of mucosal inflammation is observed endoscopically in $70 \%-90 \%$ of adult patients within a year of surgery, despite only one third of them presenting with 
symptoms [69]. Therefore, regular monitoring to check for endoscopic recurrence and disease progression after ileocolonic resection is required in postoperative $C D$ patients [70].

An early meta-analysis by Qiu et al. to evaluate the utility of FCAL in detecting suspected postoperative recurrence of $C D$ in 391 patients who underwent a previous resection, provided a sensitivity of 0.82 and a specificity of 0.61 when compared to endoscopic scores. When FCAL was used to exclusively detect a symptomatic relapse, diagnostic performance was lower, with sensitivity and specificity of 0.59 and 0.88 , respectively, although the number of patients considered were smaller $(n=183)$ [25].

A prospective clinical trial found a direct correlation between FCAL concentrations and the presence and severity of CD endoscopic recurrence after surgery, with FCAL levels greater than $100 \mu \mathrm{g} / \mathrm{g}$ showing a sensitivity of 0.89 , a specificity of 0.58 and an NPV of $91 \%$ for a Rutgeerts score equal to or higher than i2 [71].

A more recently published meta-analysis pooling data from nine studies (four already included in that by Qiu) identified $150 \mu \mathrm{g} / \mathrm{g}$ as the best cut-off point (based on its higher AUROC compared to 50, 100 and $200 \mu \mathrm{g} / \mathrm{g}$ ) when using FCAL as a surrogate marker of postoperative endoscopic recurrence in CD patients [26]. Two studies that were not included in this latest meta-analysis, due to being performed in a paediatric population and published afterwards, similarly reported low values of specificity and different optimal cut-off values. The optimal cut-off point in detecting endoscopic recurrence in paediatric CD patients was $139 \mu \mathrm{g} / \mathrm{g}$, which provided a sensitivity of 0.73 , a specificity of 0.64 , and an NPV of $70 \%$ [72]. The most recent study on this topic estimated an optimal cut-off point of $62 \mu \mathrm{g} / \mathrm{g}$, with FCAL showing a sensitivity of 0.86 , a specificity of 0.46 , and an NPV of only $71 \%$, which were not better than CRP or a score of symptoms [73].

\section{Differences in FCAL measurement by different assays}

The most commonly employed method for FCAL measurement has been enzyme-linked immunosorbent assays (ELISA). Other methods have been introduced into the clinical laboratory market in the last 10 years, mainly point-of-care tests (POCTs) based on rapid immmunochromatographic methods and fully automated immunoassays.

Rapid POCTs were developed to overcome the limitations of ELISAs since the latter require an analytical turnaround time of several hours and can only be performed when a high number of samples is available to be run in the same batch in order to reduce costs. The first POCT was launched in 2008 and it estimated FCAL levels in a semi-quantitative way, which hampered its performance $[74,75]$. A few years later, a new quantitative immmunochromatographic assay was developed (Quantum Blue by Bülhmann Laboratories) and several studies investigated its concordance with other commercially available ELISAs [76-80]. Agreement was reported as good, with concordance rates between $85 \%$ and $92.7 \%$. However, it should be noted that different cut-off points were used in each study for diagnostic purposes and in two of them the thresholds used for the POCT were different to those used in the ELISA [78, 80]. Equivalent values of sensitivity and specificity were also reported when this POCT was compared to an automated immunoassay (EliA Calprotectin from Thermo Fisher Scientific), although relevant differences were described for the two extraction devices used for FCAL [81]. Two studies from the same group revealed that the FCAL POCT had a good correlation with ELISA concentrations and constituted an accurate surrogate marker of endoscopic remission in patients with both $\mathrm{CD}$ and UC $[82,83]$.

Fully automated FCAL immunoassays have been developed to solve the aforementioned ELISA limitations while providing higher accuracy and precision, due to reduced manual handling of samples. However, it is necessary to optimise the thresholds suggested by the manufacturers and to define the most precise cut-off points for these new methods $[84,85]$.

Several studies have compared the diverse types of commercially available FCAL assays. Overall, similar analytical and diagnostic performances were found to differentiate IBD from other functional bowel disorders, but important quantitative differences in FCAL levels were described among those assays [86-89]. In one of them, the reported differences in clinical performance among assays were higher for follow-up than for diagnosis of patients with IBD [88]. Furthermore, optimal cut-off points for detecting IBD activity were higher than those in adults and differed by hundreds of $\mu \mathrm{g} / \mathrm{g}$ among manufacturers in the paediatric population [90]. In agreement with these results, a study from the UK National External Quality Assessment Service revealed up to a 3.8-fold difference between methods from different manufacturers [91], and even greater differences in specificity were observed among three ELISAs in a Danish study, with one of the assays showing a very low specificity $(0.28)$ and a prominent high false positive rate (72\%) [92]. 
Accordingly, direct comparison of absolute FCAL levels between different kits is inappropriate currently, mainly due to the variety of methods, the different extraction devices, different antibodies employed and their different source. Using a same test during the follow-up of a patient with IBD is highly advisable. Therefore, FCAL concentrations are not interchangeable among different assays, and the cut-off values may vary depending on the purpose for each particular test: diagnosis, monitoring or prediction of relapse.

\section{Current limitations in FCAL routine clinical use}

The first limitations described for FCAL as a non-invasive diagnostic marker of IBD were related to the presence of false positive results. High FCAL concentrations that are found in several non-IBD conditions is one explanation for the low specificity of FCAL compared to its relative high sensitivity.

Gastrointestinal processes identified as causing FCAL false positive results mainly include infectious diarrhoea [93], non-steroidal anti-inflammatory drug use [94], colorectal cancer or adenomatous polyps [75], coeliac disease [95], bacterial acute gastroenteritis [96], microscopic colitis [97], juvenile polyps in children [98], eosinophilic or lymphocytic colitis [99] and intestinal lymphoma [100]. In addition, proteolysis, due to increased trypsin activity, is a confounding factor in the interpretation of FCAL levels that may produce false negative results [101].

Another issue that could limit FCAL usage is pregnancy as some initial studies, not published as full-papers, reported no correlation between FCAL and clinical activity scores [102], and low performance to predict relapse [103]. However, more recent works have showed that FCAL was not altered by the physiological changes of pregnancy $[104,105]$, and thus FCAL could be useful as a biomarker to monitor IBD activity during pregnancy $[105,106]$.

An increase in FCAL values with age was also reported, although the number of studies evaluating this issue is low. The first of them found higher FCAL levels for the 65-70 age group compared to the 50-64 age group [107]. A few years later, another study described higher FCAL concentration, in healthy populations, for adults aged 60 or more than those aged 10-59 years, resulting in a different upper limit for FCAL reference range $(<51 \mu \mathrm{g} / \mathrm{g}$ for $10-59$ years vs. $<112 \mu \mathrm{g} / \mathrm{g}$ for $\geq 60$ years) [108]. Likewise, a more recent study reported higher FCAL levels in patients aged 65 or more, which had an effect on cut-off values for
IBD diagnosis, as they were 3 to 4 times higher - depending on the assay employed - than in the younger group and entailed lower sensibility for older patients [109].

Variability in FCAL levels in stool samples collected during a single day is another issue affecting its routine use in clinical practice: FCAL concentration increases the longer there is between bowel movements. So, stool samples obtained from the first bowel movement in the morning have been recommended as the best ones for measuring FCAL [110]. In contrast, another study reported no differences in FCAL levels between morning samples and those from different bowel movements on the same day [111]. Furthermore, a low variability was found across three stool samples obtained on consecutive days from patients with quiescent $\mathrm{CD}$, with reliability to identify a case (defined as FCAL above $50 \mu \mathrm{g} / \mathrm{g}$ ) being estimated as "moderately good" [112]. Therefore, it seems reasonable to prefer serial measurements of FCAL over single determinations to make clinical decisions. It has also been suggested that FCAL should be measured every 3 months when patients are within the target range, while frequency of determination should be increased to every month when FCAL values are within an uncertain $(250-500 \mu \mathrm{g} / \mathrm{g})$ or disease activity range (above $500 \mu \mathrm{g} / \mathrm{g}$ ) [113, 114].

\section{Alternative faecal biomarkers to FCAL}

FCAL has gained popularity as a routine biomarker in IBD diagnosis, monitoring and management, but other faecal biomarkers have also been investigated. Despite alternative faecal biomarkers having provided a lower amount of evidence compared to FCAL, some of them have reported promising results, with a similar or even superior performance in assessing patients with IBD.

The most studied faecal biomarker after FCAL is lactoferrin (FLAC). Similar to calprotectin, it is a major constituent protein of neutrophil granules, which are released during inflammation. Parallel analysis of FLAC and FCAL has been carried out in multiple studies assessing several aspects of IBD, including diagnosis, disease activity, correlation with clinical, endoscopic and histological features, and predictive capacity, overall showing a similar performance, with sensitivity being generally lower and specificity slightly higher than for FCAL $[115,116]$.

The first meta-analysis summarising the ability of FLAC to distinguish an IBD diagnosis from IBS reported a sensitivity of 0.78 and a specificity of 0.94 [117]. A later meta-analysis which included a larger number of patients 
and a varied group of controls (including healthy subjects, and patients with IBS and other gastrointestinal diseases) provided similar figures (sensitivity being 0.82 and specificity 0.95) for predicting an IBD diagnosis [118]. An additional meta-analysis comparing FLAC and FCAL in IBD diagnosis reported a lower performance for FLAC [17], while in assessing IBD activity FLAC provided lower sensitivity ( 0.82 vs. 0.88$)$ and higher specificity ( 0.79 vs. 0.73 ) compared to FCAL [23]. Therefore, lower sensitivity and a shorter body of supporting evidence has resulted in FLAC being used less as a biomarker in clinical practice.

Calgranulin-C (also call S100A12A) is another protein released by granulocytes that has been proposed as a useful biomarker in IBD diagnosis. It was first reported in 2007 that faecal concentrations of S100A12 were significantly higher in IBD patients while mildly elevated in bacterial infections, but not in viral ones [119]. The utility of S100A12 has been mainly evaluated for IBD diagnosis, when sensitivity was similar to FCAL, but specificity was higher, with repeated studies reporting rates above 0.90 [120]. Two recent studies that compared S100A12 with FCAL for IBD diagnosis showed the former to have the advantage, due to a higher specificity and better discriminative capacity to exclude the disease [121, 122].

Faecal haemoglobin concentration measured by faecal immunochemical tests (FIT) has been proposed as an additional reliable and cheaper alternative to FCAL in evaluating mucosal healing in UC. FIT is currently used as a primary assay for colorectal cancer screening and thus its main advantage is a wide availability in userfriendly automated analysers. It has been demonstrated that FIT performs well in predicting mucosal healing exclusively in UC, even with greater sensitivity than FCAL [123]. A recent meta-analysis including 625 UC patients from seven studies (all but one from Asia) showed pooled sensitivity and specificity of 0.77 and 0.81 , respectively [124]. Despite the promising initial findings, more evidence is required to implement FIT use in IBD routine management.

Finally, in a very detailed review on surrogate faecal biomarkers in IBD recently published by Di Ruscio et al., the performance of 17 faecal biomarkers - FCAL and FLAC were pointedly excluded due to the large number of studies leading with these proteins - are described for several IBD clinical aspects [125]. Apart from S100A12 and faecal haemoglobin, three novel markers display similar sensitivity and specificity figures to FCAL for IBD diagnosis, potentially representing non-invasive markers for IBD in the future: matrix metalloproteinase-9 [126], chitinase3-like-1 [127], and neutrophil gelatinase-associated lipocalin [128].

\section{Conclusions}

There is a large amount of evidence, summarised in several meta-analyses, to support the usefulness of FCAL in IBD assessment. Due to its high NPV, FCAL is widely used to exclude IBD in patients with clinical suspicion; its relatively high sensitivity in children and adults leads to further examinations being performed and greatly reduces the chance of a case of IBD being overlooked. Furthermore, FCAL allows relevant savings in health costs by reducing the number of endoscopies in patients with normal values. However, a lower specificity for FCAL in children could product a higher rate of false positives compared to adults. False positive FCAL results are due mostly to organic disease conditions that would require an endoscopic examination anyway.

Four meta-analyses published in recent years support the use of FCAL as a surrogate marker for endoscopic activity and mucosal healing, both in disease monitoring during treatment and after ileocolonic resection in patients with $\mathrm{CD}$, although its performance for the latter purpose was lower. High sensitivity values were reported for these clinical settings, but lower than those observed in IBD diagnosis. Sustained low FCAL values may be considered as indicators of endoscopic remission.

Elevated FCAL levels in patients with clinical remission could anticipate a future relapse, as assessed in several studies summarised in a further meta-analysis. However, FCAL was shown to have a more limited applicability for this purpose compared to others. There is general consensus that increased FCAL concentrations correlate with a higher risk of relapse, but sensibility, specificity and thresholds varied considerably among studies.

The lack of validation of cut-off values for different clinical settings is probably the main limitation of FCAL usage in clinical practice. Large quantitative differences described for the several commercially available assays are the main underlying reason, therefore patients should be evaluated by using the same FCAL assay during followup and further efforts are needed to standardise FCAL assays. In addition to the lack of interchangeability among commercial tests, the routine use of FCAL is also limited by false positive and false negative results, age-dependent reference values and intra-individual variability. Expert recommendations that support serial measurement of FCAL and avoid clinical decisions based exclusively on a single FCAL result have been provided.

Finally, several faecal markers constitute potential non-invasive predictors of inflammation in IBD patients. FLAC has been largely studied and compared to FCAL, with a slightly worse overall performance in terms of sensitivity. 
S100A12 may be a promising biomarker as it has shown higher specificity for IBD diagnosis while FIT could be a cheaper and more extensively available alternative to assess mucosal healing in patients with UC. Although many other biomarkers have been proposed as useful in IBD management, FCAL, having as yet the largest body of evidence by far, is still the most widely used and supported.

Acknowledgments: We are grateful to Melanie Radcliff for the English language revision. EJ Laserna-Mendieta is recipient of a Rio Hortega grant (CM17/00003) from Instituto de Salud Carlos III (ISCIII), Spanish Ministry of Health, Social Services and Equality, which is partly funded by the European Social Fund (period 2014-2020).

Author contributions: EJLM and AJL have written the review. Both authors accept the responsibility for the entire content of this manuscript and approved its final version before submission.

Research funding: None declared.

Employment or leadership: None declared.

Honorarium: None declared.

Competing interest: The funding organization(s) played no role in the study design; in the collection, analysis, and interpretation of data; in the writing of the report; or in the decision to submit the report for publication.

\section{References}

1. Kerkhoff C, Klempt M, Sorg C. Novel insights into structure and function of MRP8 (S100A8) and MRP14 (S100A9). Biochim Biophys Acta 1998;1448:200-11.

2. Korndörfer IP, Brueckner F, Skerra A. The crystal structure of the human (S100A8/S100A9)2 heterotetramer, calprotectin, illustrates how conformational changes of interacting alpha-helices can determine specific association of two EF-hand proteins. J Mol Biol 2007;370:887-98.

3. Fagerhol MK, Dale I, Andersson T. A radioimmunoassay for a granulocyte protein as a marker in studies on the turnover of such cells. Bull Eur Physiopathol Respir 1980;16(Suppl):273-82.

4. Steinbakk M, Naess-Andresen CF, Lingaas E, Dale I, Brandtzaeg P, Fagerhol MK. Antimicrobial actions of calcium binding leucocyte L1 protein, calprotectin. Lancet 1990;336:763-5.

5. Brandtzaeg P, Gabrielsen TO, Dale I, Müller F, Steinbakk M, Fagerhol MK. The leucocyte protein L1 (calprotectin): a putative nonspecific defence factor at epithelial surfaces. Adv Exp Med Biol 1995;371A:201-6.

6. Brun JG, Haga HJ, Bøe E, Kallay I, Lekven C, Berntzen HB, et al. Calprotectin in patients with rheumatoid arthritis: relation to clinical and laboratory variables of disease activity. J Rheumatol 1992;19:859-62.

7. Yui S, Mikami M, Yamazaki M. Induction of apoptotic cell death in mouse lymphoma and human leukemia cell lines by a calciumbinding protein complex, calprotectin, derived from inflammatory peritoneal exudate cells. J Leukoc Biol 1995;58:650-8.
8. Viemann D, Barczyk K, Vogl T, Fischer U, Sunderkötter C, Schulze-Osthoff K, et al. MRP8/MRP14 impairs endothelial integrity and induces a caspase-dependent and -independent cell death program. Blood 2007;109:2453-60.

9. Goyette J, Geczy CL. Inflammation-associated S100 proteins: new mechanisms that regulate function. Amino Acids 2011;41:821-42.

10. Johne B, Fagerhol MK, Lyberg T, Prydz H, Brandtzaeg P, NaessAndresen $\mathrm{CF}$, et al. Functional and clinical aspects of the myelomonocyte protein calprotectin. Mol Pathol 1997;50:113-23.

11. Poullis A, Foster R, Mendall MA, Fagerhol MK. Emerging role of calprotectin in gastroenterology. J Gastroenterol Hepatol 2003;18:756-62.

12. Konikoff MR, Denson LA. Role of fecal calprotectin as a biomarker of intestinal inflammation in inflammatory bowel disease. Inflamm Bowel Dis 2006;12:524-34.

13. Kostakis ID, Cholidou KG, Vaiopoulos AG, Vlachos IS, Perrea $D$, Vaos $\mathrm{G}$. Fecal calprotectin in pediatric inflammatory bowel disease: a systematic review. Dig Dis Sci 2013;58:309-19.

14. Sipponen T, Kolho KL. Fecal calprotectin in diagnosis and clinical assessment of inflammatory bowel disease. Scand J Gastroenterol 2015;50:74-80.

15. Von Roon AC, Karamountzos L, Purkayastha S, Reese GE, Darzi AW, Teare JP, et al. Diagnostic precision of fecal calprotectin for inflammatory bowel disease and colorectal malignancy. Am J Gastroenterol 2007;102:803-13.

16. Van Rheenen PF, Van de Vijver E, Fidler V. Faecal calprotectin for screening of patients with suspected inflammatory bowel disease: diagnostic meta-analysis. Br Med J 2010;341:c3369.

17. Menees SB, Powell C, Kurlander J, Goel A, Chey WD. A metaanalysis of the utility of $C$-reactive protein, erythrocyte sedimentation rate, fecal calprotectin, and fecal lactoferrin to exclude inflammatory bowel disease in adults with IBS. Am J Gastroenterol 2015;110:444-54.

18. Kopylov U, Yung DE, Engel T, Avni T, Battat R, Ben-Horin S, et al. Fecal calprotectin for the prediction of small-bowel Crohn's disease by capsule endoscopy: a systematic review and metaanalysis. Eur J Gastroenterol Hepatol 2016;28:1137-44.

19. Henderson P, Anderson NH, Wilson DC. The diagnostic accuracy of fecal calprotectin during the investigation of suspected pediatric inflammatory bowel disease: a systematic review and meta-analysis. Am J Gastroenterol 2014;109:637-45.

20. Degraeuwe PL, Beld MP, Ashorn M, Canani RB, Day AS, Diamanti A, et al. Faecal calprotectin in suspected paediatric inflammatory bowel disease. J Pediatr Gastroenterol Nutr 2015;60:339-46.

21. Holtman GA, Lisman-van Leeuwen Y, Reitsma JB, Berger MY. Noninvasive tests for inflammatory bowel disease: a meta-analysis. Pediatrics 2016;137:e20152126.

22. Lin JF, Chen JM, Zuo JH, Yu A, Xiao ZJ, Deng FH, et al. Meta-analysis: fecal calprotectin for assessment of inflammatory bowel disease activity. Inflamm Bowel Dis 2014;20:1407-15.

23. Mosli MH, Zou G, Garg SK, Feagan SG, MacDonald JK, Chande N, et al. C-reactive protein, fecal calprotectin, and stool lactoferrin for detection of endoscopic activity in symptomatic inflammatory bowel disease patients: a systematic review and metaanalysis. Am J Gastroenterol 2015;110:802-19.

24. Mao R, Xiao YL, Gao X, Chen BL, He Y, Yang L, et al. Fecal calprotectin in predicting relapse of inflammatory bowel diseases: 
a meta-analysis of prospective studies. Inflamm Bowel Dis 2012;18:1894-9.

25. Qiu Y, Mao R, Chen BL, He Y, Zeng ZR, Xue L, et al. Fecal calprotectin for evaluating postoperative recurrence of Crohn's disease: a meta-analysis of prospective studies. Inflamm Bowel Dis 2015;21:315-22.

26. Tham YS, Yung DE, Fay S, Yamamoto T, Ben-Horin S, Eliakim $\mathrm{R}$, et al. Fecal calprotectin for detection of postoperative endoscopic recurrence in Crohn's disease: systematic review and meta-analysis. Therap Adv Gastroenterol 2018;11:1756284818785571.

27. Wang S, Wang Z, Shi H, Heng L, Juan W, Yuan B, et al. Faecal calprotectin concentrations in gastrointestinal diseases. J Int Med Res 2013;41:1357-61.

28. Kopylov U, Rosenfeld G, Bressler B, Seidman E. Clinical utility of fecal biomarkers for the diagnosis and management of inflammatory bowel disease. Inflamm Bowel Dis 2014;20:742-56.

29. Olafsdottir E, Aksnes L, Fluge G, Berstad A. Faecal calprotectin levels in infants with infantile colic, healthy infants, children with inflammatory bowel disease, children with recurrent abdominal pain and healthy children. Acta Paediatr 2002;91:45-50.

30. Oord T, Hornung N. Fecal calprotectin in healthy children. Scand J Clin Lab Invest 2014;74:254-8.

31. Zhu Q, Li F, Wang J, Shen L, Sheng X. Fecal calprotectin in healthy children aged 1-4 years. PLoS One 2016;11:e0150725.

32. Holtman GA, Lisman-van Leeuwen Y, Day AS, Fagerberg UL, Henderson P, Leach ST, et al. Use of laboratory markers in addition to symptoms for diagnosis of inflammatory bowel disease in children: a meta-analysis of individual patient data. JAMA Pediatr 2017;171:984-91.

33. Yang Z, Clark N, Park KT. Effectiveness and cost-effectiveness of measuring fecal calprotectin in diagnosis of inflammatory bowel disease in adults and children. Clin Gastroenterol Hepatol 2014;12:253-62.e2.

34. Mindemark M, Larsson A. Ruling out IBD: estimation of the possible economic effects of pre-endoscopic screening with F-calprotectin. Clin Biochem 2012;45:552-5.

35. Waugh N, Cummins E, Royle P, Kandala NB, Shyangdan D, Arasaradnam R, et al. Faecal calprotectin testing for differentiating amongst inflammatory and non-inflammatory bowel diseases: systematic review and economic evaluation. Health Technol Assess 2013;17:xv-xix, 1-211.

36. Bressler B, Panaccione R, Fedorak RN, Seidman EG. Clinicians' guide to the use of fecal calprotectin to identify and monitor disease activity in inflammatory bowel disease. Can J Gastroenterol Hepatol 2015;29:369-72.

37. Morris MW, Stewart SA, Heisler C, Sandborn WJ, Loftus EV, Zello GA, et al. Biomarker-based models outperform patientreported scores in predicting endoscopic inflammatory disease activity. Inflamm Bowel Dis 2018;24:277-85.

38. Bryant RV, Burger DC, Delo J, Walsh AJ, Thomas S, von Herbay A, et al. Beyond endoscopic mucosal healing in UC: histological remission better predicts corticosteroid use and hospitalisation over 6 years of follow-up. Gut 2016;65:408-14.

39. Peyrin-Biroulet L, Bressenot A, Kampman W. Histologic remission: the ultimate therapeutic goal in ulcerative colitis? Clin Gastroenterol Hepatol 2014;12:929-34.e2.

40. Riley SA, Mani V, Goodman MJ, Dutt S, Herd ME. Microscopic activity in ulcerative colitis: what does it mean? Gut 1991;32:174-8.

41. Zittan E, Kelly OB, Kirsch R, Milgrom R, Burns J, Nguyen GC, et al. Low fecal calprotectin correlates with histological remission and mucosal healing in ulcerative colitis and colonic crohn's disease. Inflamm Bowel Dis 2016;22:623-30.

42. Theede K, Holck S, Ibsen P, Kallemose T, Nordgaard-Lassen I, Nielsen AM. Fecal calprotectin predicts relapse and histological mucosal healing in ulcerative colitis. Inflamm Bowel Dis 2016;22:1042-8.

43. Guardiola J, Lobatón T, Rodríguez-Alonso L, Ruiz-Cerulla A, Arajol C, Loayza C, et al. Fecal level of calprotectin identifies histologic inflammation in patients with ulcerative colitis in clinical and endoscopic remission. Clin Gastroenterol Hepatol 2014;12:1865-70.

44. Theede K, Holck S, Ibsen P, Ladelund S, Nordgaard-Lassen I, Nielsen AM. Level of fecal calprotectin correlates with endoscopic and histologic inflammation and identifies patients with mucosal healing in ulcerative colitis. Clin Gastroenterol Hepatol 2015;13:1929-36.e1.

45. Aomatsu T, Yoden A, Matsumoto K, Kimura E, Inoue K, Andoh A, et al. Fecal calprotectin is a useful marker for disease activity in pediatric patients with inflammatory bowel disease. Dig Dis Sci 2011;56:2372-7.

46. Diamanti A, Colistro F, Basso MS, Papadatou B, Francalanci P, Bracci $F$, et al. Clinical role of calprotectin assay in determining histological relapses in children affected by inflammatory bowel diseases. Inflamm Bowel Dis 2008;14:1229-35.

47. Canani RB, Terrin G, Rapacciuolo L, Miele E, Siani MC, Puzone $C$, et al. Faecal calprotectin as reliable non-invasive marker to assess the severity of mucosal inflammation in children with inflammatory bowel disease. Dig Liver Dis 2008;40:547-53.

48. Tibble JA, Sigthorsson G, Bridger S, Fagerhol MK, Bjarnason I. Surrogate markers of intestinal inflammation are predictive of relapse in patients with inflammatory bowel disease. Gastroenterology 2000;119:15-22.

49. Sandborn WJ, Feagan BG, Hanauer SB, Lochs H, Löfberg R, Modigliani R, et al. A review of activity indices and efficacy endpoints for clinical trials of medical therapy in adults with Crohn's disease. Gastroenterology 2002;122:512-30.

50. Jauregui-Amezaga A, López-Cerón M, Aceituno M, Jimeno M, Rodríguez de Miguel C, Pinó-Donnay S, et al. Accuracy of advanced endoscopy and fecal calprotectin for prediction of relapse in ulcerative colitis: a prospective study. Inflamm Bowel Dis 2014;20:1187-93.

51. Mooiweer E, Severs M, Schipper ME, Fidder HH, Siersema PD, Laheij RJ, et al. Low fecal calprotectin predicts sustained clinical remission in inflammatory bowel disease patients: a plea for deep remission. J Crohns Colitis 2015;9:50-5.

52. Heida A, Park KT, van Rheenen PF. Clinical utility of fecal calprotectin monitoring in asymptomatic patients with inflammatory bowel disease: a systematic review and practical guide. Inflamm Bowel Dis 2017;23:894-902.

53. Zhulina Y, Cao Y, Amcoff K, Carlson M, Tysk C, Halfvarson J. The prognostic significance of faecal calprotectin in patients with inactive inflammatory bowel disease. Aliment Pharmacol Ther 2016;44:495-504.

54. Walkiewicz D, Werlin SL, Fish D, Scanlon M, Hanaway P, Kugathasan $\mathrm{S}$. Fecal calprotectin is useful in predicting disease relapse in pediatric inflammatory bowel disease. Inflamm Bowel Dis 2008;14:669-73.

55. Van Rheenen PF. Role of fecal calprotectin testing to predict relapse in teenagers with inflammatory bowel disease who report full disease control. Inflamm Bowel Dis 2012;18:2018-25. 
56. Diederen K, Hoekman DR, Leek A, Wolters VM, Hummel TZ, de Meij TG, et al. Raised faecal calprotectin is associated with subsequent symptomatic relapse, in children and adolescents with inflammatory bowel disease in clinical remission. Aliment Pharmacol Ther 2017;45:951-60.

57. Sipponen T, Kolho KL. Faecal calprotectin in children with clinically quiescent inflammatory bowel disease. Scand J Gastroenterol 2010;45:872-7.

58. Ho GT, Lee HM, Brydon G, Ting T, Hare N, Drummond H, et al. Fecal calprotectin predicts the clinical course of acute severe ulcerative colitis. Am J Gastroenterol 2009;104:673-8.

59. De Vos M, Dewit O, D’Haens G, Baert F, Fontaine F, Vermeire S, et al. Fast and sharp decrease in calprotectin predicts remission by infliximab in anti-TNF naïve patients with ulcerative colitis. J Crohns Colitis 2012;6:557-62.

60. De Vos M, Louis EJ, Jahnsen J, Vandervoort JG, Noman M, Dewit $\mathrm{O}$, et al. Consecutive fecal calprotectin measurements to predict relapse in patients with ulcerative colitis receiving infliximab maintenance therapy. Inflamm Bowel Dis 2013;19:2111-7.

61. af Björkesten CG, Nieminen U, Turunen U, Arkkila P, Sipponen T, Färkkilä M. Surrogate markers and clinical indices, alone or combined, as indicators for endoscopic remission in antiTNF-treated luminal Crohn's disease. Scand J Gastroenterol 2012;47:528-37.

62. Molander P, af Björkesten CG, Mustonen H, Haapamäki J, Vauhkonen M, Kolho KL, et al. Fecal calprotectin concentration predicts outcome in inflammatory bowel disease after induction therapy with TNF $\alpha$ blocking agents. Inflamm Bowel Dis 2012;18:2011-7.

63. Ferreiro-Iglesias R, Barreiro-de Acosta M, Lorenzo-Gonzalez A, Dominguez-Muñoz JE. Accuracy of consecutive fecal calprotectin measurements to predict relapse in inflammatory bowel disease patients under maintenance with anti-TNF therapy: a prospective longitudinal cohort study. J Clin Gastroenterol 2018;52:229-34.

64. Louis E, Mary JY, Vernier-Massouille G, Grimaud JC, Bouhnik $\mathrm{Y}$, Laharie D, et al. Maintenance of remission among patients with Crohn's disease on antimetabolite therapy after infliximab therapy is stopped. Gastroenterology 2012;142:63-70.e5.

65. Molander P, Färkkilä M, Ristimäki A, Salminen K, Kemppainen $\mathrm{H}$, Blomster T, et al. Does fecal calprotectin predict short-term relapse after stopping TNF $\alpha$-blocking agents in inflammatory bowel disease patients in deep remission? J Crohns Colitis 2015;9:33-40.

66. Kennedy NA, Warner B, Johnston EL, Flanders L, Hendy P, Ding NS, et al. Relapse after withdrawal from anti-TNF therapy for inflammatory bowel disease: an observational study, plus systematic review and meta-analysis. Aliment Pharmacol Ther 2016;43:910-23.

67. Bortlik M, Duricova D, Machkova N, Hruba V, Lukas M, Mitrova $\mathrm{K}$, et al. Discontinuation of anti-tumor necrosis factor therapy in inflammatory bowel disease patients: a prospective observation. Scand J Gastroenterol 2016;51:196-202.

68. Connelly TM, Messaris E. Predictors of recurrence of Crohn's disease after ileocolectomy: a review. World J Gastroenterol 2014;20:14393-406.

69. Buisson A, Chevaux JB, Allen PB, Bommelaer G, Peyrin-Biroulet L. Review article: the natural history of postoperative Crohn's disease recurrence. Aliment Pharmacol Ther 2012;35:625-33.

70. De Cruz P, Kamm MA, Hamilton AL, Ritchie KJ, Krejany EO, Gorelik A, et al. Crohn's disease management after intestinal resection: a randomised trial. Lancet 2015;385:1406-17.
71. Wright EK, Kamm MA, De Cruz P, Hamilton AL, Ritchie KJ, Krejany EO, et al. Measurement of fecal calprotectin improves monitoring and detection of recurrence of Crohn's disease after surgery. Gastroenterology 2015;148:938-47.e1.

72. Hukkinen M, Pakarinen MP, Merras-Salmio L, Koivusalo A, Rintala R, Kolho KL. Fecal calprotectin in the prediction of postoperative recurrence of Crohn's disease in children and adolescents. J Pediatr Surg 2016;51:1467-72.

73. Verdejo C, Hervías D, Roncero O, Arias A, Bouhmidi A, Lorente R, et al. Fecal calprotectin is not superior to serum C-reactive protein or the Harvey-Bradshaw index in predicting postoperative endoscopic recurrence in Crohn's disease. Eur J Gastroenterol Hepatol 2018;30:1521-7.

74. Vestergaard TA, Nielsen SL, Dahlerup JF, Hornung N. Fecal calprotectin: assessment of a rapid test. Scand J Clin Lab Invest 2008;68:343-7.

75. Damms A, Bischoff SC. Validation and clinical significance of a new calprotectin rapid test for the diagnosis of gastrointestinal diseases. Int J Colorectal Dis 2008;23:985-92.

76. Kolho KL, Turner D, Veereman-Wauters G, Sladek M, de Ridder L, Shaoul R, et al. Rapid test for fecal calprotectin levels in children with Crohn disease. J Pediatr Gastroenterol Nutr 2012;55:436-9.

77. Coorevits L, Baert FJ, Vanpoucke HJ. Faecal calprotectin: comparative study of the Quantum Blue rapid test and an established ELISA method. Clin Chem Lab Med 2013;51:825-31.

78. Dolci A, Panteghini M. Comparative study of a new quantitative rapid test with an established ELISA method for faecal calprotectin. Clin Chim Acta 2012;413:350-1.

79. Wassell J, Wallage M, Brewer E. Evaluation of the Quantum Blue $^{\circledR}$ rapid test for faecal calprotectin. Ann Clin Biochem 2012;49(Pt 1):55-8.

80. Sydora MJ, Sydora BC, Fedorak RN. Validation of a point-of-care desk top device to quantitate fecal calprotectin and distinguish inflammatory bowel disease from irritable bowel syndrome. J Crohns Colitis 2012;6:207-14.

81. Oyaert M, Trouvé C, Baert F, De Smet D, Langlois M, Vanpoucke $\mathrm{H}$. Comparison of two immunoassays for measurement of faecal calprotectin in detection of inflammatory bowel disease: (pre)-analytical and diagnostic performance characteristics. Clin Chem Lab Med 2014;52:391-7.

82. Lobatón T, Rodríguez-Moranta F, Lopez A, Sánchez E, RodríguezAlonso L, Guardiola J. A new rapid quantitative test for fecal calprotectin predicts endoscopic activity in ulcerative colitis. Inflamm Bowel Dis 2013;19:1034-42.

83. Lobatón T, López-García A, Rodríguez-Moranta F, Ruiz A, Rodríguez L, Guardiola J. A new rapid test for fecal calprotectin predicts endoscopic remission and postoperative recurrence in Crohn's disease. J Crohns Colitis 2013;7:e641-51.

84. De Sloovere MM, De Smet D, Baert FJ, Debrabandere J, Vanpoucke HJ. Analytical and diagnostic performance of two automated fecal calprotectin immunoassays for detection of inflammatory bowel disease. Clin Chem Lab Med 2017;55:1435-46.

85. Delefortrie Q, Schatt P, Grimmelprez A, Gohy P, Deltour D, Collard G, et al. Comparison of the Liaison ${ }^{\circledR}$ Calprotectin kit with a well established point of care test (Quantum Blue - BühlmannAlere $^{\circledR}$ ) in terms of analytical performances and ability to detect relapses amongst a Crohn population in follow-up. Clin Biochem 2016;49:268-73.

86. Jang HW, Kim HS, Park SJ, Hong SP, Kim TI, Kim WH, et al. Accuracy of three different fecal calprotectin tests in the diagnosis of inflammatory bowel disease. Intest Res 2016;14:305-13. 
87. Prell C, Nagel D, Freudenberg F, Schwarzer A, Koletzko S. Comparison of three tests for faecal calprotectin in children and young adults: a retrospective monocentric study. BMJ Open 2014; 4:e004558.

88. Labaere D, Smismans A, Van Olmen A, Christiaens P, D'Haens $G$, Moons V, et al. Comparison of six different calprotectin assays for the assessment of inflammatory bowel disease. United European Gastroenterol J 2014;2:30-7.

89. Oyaert M, Boel A, Jacobs J, Van den Bremt S, De Sloovere M, Vanpoucke $\mathrm{H}$, et al. Analytical performance and diagnostic accuracy of six different faecal calprotectin assays in inflammatory bowel disease. Clin Chem Lab Med 2017;55:1564-73.

90. Kittanakom S, Shajib MS, Garvie K, Turner J, Brooks D, Odeh S, et al. Comparison of fecal calprotectin methods for predicting relapse of pediatric inflammatory bowel disease. Can J Gastroenterol Hepatol 2017;2017:1450970.

91. Whitehead SJ, French J, Brookes MJ, Ford C, Gama R. Betweenassay variability of faecal calprotectin enzyme-linked immunosorbent assay kits. Ann Clin Biochem 2013;50(Pt 1):53-61.

92. Mirsepasi-Lauridsen HC, Bachmann Holmetoft U, Ingdam Halkjær S, Angeliki Krogfelt K, Munk Petersen A. Comparison of three commercial fecal calprotectin ELISA test kits used in patients with Inflammatory Bowel Disease. Scand J Gastroenterol 2016;51:211-7.

93. Shastri YM, Bergis D, Povse N, Schäfer V, Shastri S, Weindel $M$, et al. Prospective multicenter study evaluating fecal calprotectin in adult acute bacterial diarrhea. Am J Med 2008;121:1099-106.

94. Tibble JA, Sigthorsson G, Foster R, Scott D, Fagerhol MK, Roseth A, et al. High prevalence of NSAID enteropathy as shown by a simple faecal test. Gut 1999;45:362-6.

95. Carroccio A, Iacono G, Cottone M, Di Prima L, Cartabellotta F, Cavataio F, et al. Diagnostic accuracy of fecal calprotectin assay in distinguishing organic causes of chronic diarrhea from irritable bowel syndrome: a prospective study in adults and children. Clin Chem 2003;49(6 Pt 1):861-7.

96. Sýkora J, Siala K, Huml M, Varvařovská J, Schwarz J, Pomahačová R. Evaluation of faecal calprotectin as a valuable non-invasive marker in distinguishing gut pathogens in young children with acute gastroenteritis. Acta Paediatr 2010;99:1389-95.

97. von Arnim U, Wex T, Ganzert C, Schulz C, Malfertheiner P. Fecal calprotectin: a marker for clinical differentiation of microscopic colitis and irritable bowel syndrome. Clin Exp Gastroenterol 2016;9:97-103.

98. Kolho KL, Raivio T, Lindahl H, Savilahti E. Fecal calprotectin remains high during glucocorticoid therapy in children with inflammatory bowel disease. Scand J Gastroenterol 2006;41:720-5.

99. Komraus M, Wos H, Wiecek S, Kajor M, Grzybowska-Chlebowczyk U. Usefulness of faecal calprotectin measurement in children with various types of inflammatory bowel disease. Mediators Inflamm 2012;2012:608249.

100. Costa F, Mumolo MG, Bellini M, Romano MR, Ceccarelli L, Arpe $P$, et al. Role of faecal calprotectin as non-invasive marker of intestinal inflammation. Dig Liver Dis 2003;35:642-7.

101. Dumoulin EN, Van Biervliet S, Langlois MR, Delanghe JR. Proteolysis is a confounding factor in the interpretation of faecal calprotectin. Clin Chem Lab Med 2015;53:65-71.

102. Shitrit A, Miznikov I, Adar T, Grisaru-Granovsky S, Koslowsky $B$, Livovsky D, et al. Limitations in using fecal calprotectin as a biomarker of IBD disease activity during pregnancy. Gastroenterology 2015;148(Suppl 1):S452.

103. Kanis S, de Lima A, Van Oorschot V, Van der Woude C. Fecal calprotectine is a poor predictor of IBD relapse during pregnancy. Gastroenterology 2016;150(Suppl 1):S556.

104. Bálint A, Berényi A, Farkas K, Pallagi Kunstár É, Altorjay Á, Csonka A, et al. Pregnancy does not affect fecal calprotectin concentration in healthy women. Turk J Gastroenterol 2017;28:171-5.

105. Julsgaard M, Hvas CL, Gearry RB, Vestergaard T, Fallingborg J, Svenningsen $\mathrm{L}$, et al. Fecal calprotectin is not affected by pregnancy: clinical implications for the management of pregnant patients with inflammatory bowel disease. Inflamm Bowel Dis 2017;23:1240-6.

106. Kammerlander H, Nielsen J, Kjeldsen J, Knudsen T, Gradel $\mathrm{KO}$, Friedman S, et al. Fecal calprotectin during pregnancy in women with moderate-severe inflammatory bowel disease. Inflamm Bowel Dis 2018;24:839-48.

107. Poullis A, Foster R, Shetty A, Fagerhol MK, Mendall MA. Bowel inflammation as measured by fecal calprotectin: a link between lifestyle factors and colorectal cancer risk. Cancer Epidemiol Biomarkers Prev 2004;13:279-84.

108. Joshi S, Lewis SJ, Creanor S, Ayling RM. Age-related faecal calprotectin, lactoferrin and tumour M2-PK concentrations in healthy volunteers. Ann Clin Biochem 2010;47(Pt 3):259-63.

109. Padoan A, D'Incà R, Scapellato ML, De Bastiani R, Caccaro R, Mescoli $C$, et al. Improving IBD diagnosis and monitoring by understanding preanalytical, analytical and biological fecal calprotectin variability. Clin Chem Lab Med 2018;56:1926-35.

110. Lasson A, Stotzer PO, Öhman L, Isaksson S, Sapnara M, Strid $\mathrm{H}$. The intra-individual variability of faecal calprotectin: a prospective study in patients with active ulcerative colitis. J Crohns Colitis 2015;9:26-32.

111. Kristensen V, Malmstrøm GH, Skar V, Røseth A, Moum B. Clinical importance of faecal calprotectin variability in inflammatory bowel disease: intra-individual variability and standardisation of sampling procedure. Scand J Gastroenterol 2016;51:548-55.

112. Naismith GD, Smith LA, Barry SJ, Munro JI, Laird S, Rankin K, et al. A prospective single-centre evaluation of the intra-individual variability of faecal calprotectin in quiescent Crohn's disease. Aliment Pharmacol Ther 2013;37:613-21.

113. Van Rheenen P. Do not read single calprotectin measurements in isolation when monitoring your patients with inflammatory bowel disease. Inflamm Bowel Dis 2014;20:1416-7.

114. Louis E. Fecal calprotectin: towards a standardized use for inflammatory bowel disease management in routine practice. J Crohns Colitis 2015;9:1-3.

115. Gisbert JP, McNicholl AG, Gomollon F. Questions and answers on the role of fecal lactoferrin as a biological marker in inflammatory bowel disease. Inflamm Bowel Dis 2009;15:1746-54.

116. Abraham BP, Kane S. Fecal markers: calprotectin and lactoferrin. Gastroenterol Clin North Am 2012;41:483-95.

117. Zhou XL, Xu W, Tang XX, Luo LS, Tu JF, Zhang CJ, et al. Fecal lactoferrin in discriminating inflammatory bowel disease from irritable bowel syndrome: a diagnostic meta-analysis. BMC Gastroenterol 2014;14:121.

118. Wang Y, Pei F, Wang X, Sun Z, Hu C, Dou H. Diagnostic accuracy of fecal lactoferrin for inflammatory bowel disease: a metaanalysis. Int J Clin Exp Pathol 2015;8:12319-32.

119. Kaiser T, Langhorst J, Wittkowski H, Becker K, Friedrich AW, Rueffer A, et al. Faecal S100A12 as a non-invasive marker 
distinguishing inflammatory bowel disease from irritable bowel syndrome. Gut 2007;56:1706-13.

120. van de Logt F, Day AS. S100A12: a noninvasive marker of inflammation in inflammatory bowel disease. J Dig Dis 2013;14:62-7.

121. Whitehead SJ, Ford C, Gama RM, Ali A, McKaig B, Waldron $J$, et al. Effect of faecal calprotectin assay variability on the management of inflammatory bowel disease and potential role of faecal S100A12. J Clin Pathol 2017;70:1049-56.

122. Heida A, Van de Vijver E, van Ravenzwaaij D, Van Biervliet S, Hummel TZ, Yuksel Z, et al. Predicting inflammatory bowel disease in children with abdominal pain and diarrhoea: calgranulin- $C$ versus calprotectin stool tests. Arch Dis Child 2018;103:565-71.

123. Kato J, Hiraoka S, Nakarai A, Takashima S, Inokuchi T, Ichinose M. Fecal immunochemical test as a biomarker for inflammatory bowel diseases: can it rival fecal calprotectin? Intest Res 2016;14:5-14.

124. Dai C, Jiang M, Sun MJ, Cao Q. Fecal immunochemical test for predicting mucosal healing in ulcerative colitis patients: a systematic review and meta-analysis. J Gastroenterol Hepatol 2018;33:990-7.

125. Di Ruscio M, Vernia F, Ciccone A, Frieri G, Latella G. Surrogate fecal biomarkers in inflammatory bowel disease: rivals or complementary tools of fecal calprotectin? Inflamm Bowel Dis 2017;24:78-92.

126. Farkas K, Saródi Z, Bálint A, Földesi I, Tiszlavicz L, Szűcs $M$, et al. The diagnostic value of a new fecal marker, matrix metalloprotease-9, in different types of inflammatory bowel diseases. J Crohns Colitis 2015;9:231-7.

127. Buisson A, Vazeille E, Minet-Quinard R, Goutte M, Bouvier D, Goutorbe $F$, et al. Faecal chitinase 3-like 1 is a reliable marker as accurate as faecal calprotectin in detecting endoscopic activity in adult patients with inflammatory bowel diseases. Aliment Pharmacol Ther 2016;43:1069-79.

128. Thorsvik S, Damås JK, Granlund AV, Flo TH, Bergh K, Ø stvik $A E$, et al. Fecal neutrophil gelatinase-associated lipocalin as a biomarker for inflammatory bowel disease. J Gastroenterol Hepatol 2017;32:128-35. 